\title{
The Effect of Precipitants on Ce-La Solid Solution Prepared from Mixed Rare Earth Chloride by a Co-Precipitation Method
}

\author{
Xue Han*, Hongrui Hao and Ronggui Guo ${ }^{1}$ \\ ${ }^{1}$ Institute of Rare Earth Metallurgical Materials, General Research Institute for Non-Ferrous Metals, Beijing 100088, China
}

\begin{abstract}
Ce-La solid solution were prepared from mixed rare earth chloride via the co-precipitation method using various precipitants: urea, $\mathrm{Na}_{2} \mathrm{CO}_{3}, \mathrm{NaHCO}_{3},\left(\mathrm{NH}_{4}\right)_{2} \mathrm{CO}_{3}$ and $\mathrm{NH}_{4} \mathrm{HCO}_{3}$. The effects of the precipitants on the physicochemical properties, crystal structure and morphology of the Ce-La solid solution are investigated. The CL-urea sample displayed the largest surface area and the most uniform morphology. $\left(\mathrm{NH}_{4}\right)_{2} \mathrm{CO}_{3}$ and $\mathrm{NH}_{4} \mathrm{HCO}_{3}$ are confirmed to be more suitable precipitant than $\mathrm{Na}_{2} \mathrm{CO}_{3}$ and $\mathrm{NaHCO}_{3}$ for Ce-La solid solution preparation, because of the higher surface and less impurity residue of the corresponding samples. The effect of reverse method duing precipitation on Ce-La solid solution properties was not significant when the precipitant was excessive.
\end{abstract}

\section{Introduction}

Ceria has been extensively studied in recent years because of its wide range of potential applications in heterogeneous catalysis [1-5]. That is owing to two important properties: (i) the redox couple, $\mathrm{Ce}^{3+} / \mathrm{Ce}^{4+}$ with its ability to shift between $\mathrm{Ce}_{2} \mathrm{O}_{3}$ and $\mathrm{CeO}_{2}$ under oxidizing and reducing conditions respectively; (ii) the ease of formation of labile oxygen vacancies and oxide ion storage [6, 7]. However, under elevated conditions ceria becomes inefficient with time and many innate properties will be affected [8]. Hence, ceria is commonly combined with other metal ions to make solid solutions with improved properties.

It is now well established that $\mathrm{Zr}^{4+}$ incorporation greatly enhances the surface area, thermal stability and oxygen storage/release capacity (OSC) of ceria, resulting in superior catalytic properties, and has been used as an important material in many catalysis application [9-15]. However, Reddy and his co-workers had systematically investigated the relative efficacies of zirconium and lanthanum in ceria solid solutions and demonstrated that compared to $\mathrm{Ce}_{1-\mathrm{x}} \mathrm{Zr}_{\mathrm{x}} \mathrm{O}_{2}$, the $\mathrm{Ce}_{1-\mathrm{x}} \mathrm{La}_{\mathrm{x}} \mathrm{O}_{2-\delta}$ solid solution (CL) sample showed a high OSC, better thermal stability and enhanced soot oxidation activity [16]. La doping greatly increased the OSC value of ceria because more oxygen vacancies were created by substitution of $\mathrm{Ce}^{4+}$ cations with $\mathrm{La}^{3+}$ cations to keep charge neutrality [17]. These newly generated defects are expected to induce more number of surface active oxygen species and improve the rate of diffusion of bulk oxygen to the surface and exchange of oxygen with the environment thereby progress in the catalytic performance [18]. The oxygen vacancies also helped ceria to create a strong metal-support interaction, and promote the dispersion of noble metals $[19,20]$. Comparing to pure ceria, the advantage of $\mathrm{CL}$ were found in many catalytic applications, for example soot oxidation [6, 21], CO oxidation [22-24], methane oxidation [25, 26], steam reforming of methane [27] and water-gas shift reaction [28-30].

Our previous work showed that the proper $\mathrm{La} /(\mathrm{Ce}+\mathrm{La})$ molar ratio is $20 \sim 50 \mathrm{~mol} . \%$ of $\mathrm{Ce}_{1-\mathrm{x}} \mathrm{La}_{\mathrm{x}} \mathrm{O}_{\mathrm{y}}$ solid solution supported $\mathrm{Rh}$ catalysts for ethanol oxidative steam reforming reaction [31]. The similar phenomenon was also be found in water-gas shift and combustion of methane reaction $[25,30]$. Surprisingly that the actual $\mathrm{La} /(\mathrm{Ce}+\mathrm{La})$ molar ratio in rare earth ore is coincidentally in the range mentioned above, for example, Ce: $\mathrm{La}$ is about 5:3 in the typical bastnasite (Bayan Obo, China). In rare earth metallurgical industry, mixed rare earth chloride $\left(\mathrm{RECl}_{3} \cdot 6 \mathrm{H}_{2} \mathrm{O}\right)$ can be conveniently produced from bastnasite or/and monazite by hydrochloric acid chlorination. After separation of other more useful and expensive rare earth element such as $\mathrm{Pr}, \mathrm{Nd}$ and $\mathrm{Sm}$, the $\mathrm{RECl}_{3} \cdot 6 \mathrm{H}_{2} \mathrm{O}$ turned to be a cheap industrial raw and processed materials contained highly purified mixed $\mathrm{Ce}$ and $\mathrm{La}(\mathrm{RE}=\mathrm{Ce}$ and $\mathrm{La},>99 \%)$. However, the separation of $\mathrm{Ce}$ and $\mathrm{La}$ is a complicated process because of their similar physical and chemical properties. Therefore, we were inspired that $\mathrm{CL}$ prepared from mixed rare earth chloride $\left(\mathrm{RECl}_{3} \cdot 6 \mathrm{H}_{2} \mathrm{O}, \mathrm{RE}=\mathrm{Ce}\right.$ and $\left.\mathrm{La},>99 \%\right)$ directly will save plenty of instruments, materials, energy and time, which is a great improvement in environmental and economic view.

$\mathrm{Ce}_{1-\mathrm{x}} \mathrm{La}_{\mathrm{x}} \mathrm{O}_{\mathrm{y}}$ solid solution (CL) can be prepared by many methods, but $\mathrm{Ce}$ and $\mathrm{La}$ will exhibit phase segregation with La loading and calcination temperature increasing, and the range limits can be affected by the preparation method [32]. It was reported that thermal decomposition of $\mathrm{Ce}_{1-\mathrm{x}} \mathrm{La}_{\mathrm{x}}(\mathrm{OH}) \mathrm{CO}_{3}$ (a precipitates from co-precipitation method) favored the formation of CL and avoided phase segregation [33].

Inspired by all of the above, in this work, $\mathrm{Ce}_{1-\mathrm{x}} \mathrm{La}_{\mathrm{x}} \mathrm{O}_{\mathrm{y}}$ solid solution was prepared by co-precipitation method using mixed rare earth chloride $\left(\mathrm{RECl}_{3} \cdot 6 \mathrm{H}_{2} \mathrm{O}, \mathrm{RE}=\mathrm{Ce}\right.$ and $\mathrm{La},>99 \%$ ) as precursor, urea, $\mathrm{Na}_{2} \mathrm{CO}_{3}, \mathrm{NaHCO}_{3}$, $\left(\mathrm{NH}_{4}\right)_{2} \mathrm{CO}_{3}$ and $\mathrm{NH}_{4} \mathrm{HCO}_{3}$ as precipitant. The effects of the precipitants on the physicochemical properties, crystal structure and morphology of the Ce-La solid solution are investigated.

\section{Experimental}

\subsection{Catalyst preparation}

$\mathrm{Ce}-\mathrm{La}$ solid solution was prepared by co-precipitation method using mixed rare earth chloride $\left(\mathrm{RECl}_{3} \cdot 6 \mathrm{H}_{2} \mathrm{O}\right.$, $\mathrm{RE}=\mathrm{Ce}, \mathrm{La}, 99 \%$, La/Ce+La $=38$ mol. \%, Baotou Xinye) 
as precursor. Typically, $30 \mathrm{~g} \mathrm{RECl} \cdot 6 \mathrm{H}_{2} \mathrm{O}$ was dissolved in $200 \mathrm{~mL}$ of water. Then, $0.5 \mathrm{~mol} \mathrm{Na}_{2} \mathrm{CO}_{3}, \mathrm{NaHCO}_{3}$, $\left(\mathrm{NH}_{4}\right)_{2} \mathrm{CO}_{3}$ and $\mathrm{NH}_{4} \mathrm{HCO}_{3}$ solution was added into the mixed solution drop by drop with stirring. The precipitate was washed by $0.5 \mathrm{~L}$ deionized water and dried at $60{ }^{\circ} \mathrm{C}$ for $12 \mathrm{~h}$, then thermally treated in a furnace at $500^{\circ} \mathrm{C}$ for $5 \mathrm{~h}$ in air (denoted as CL-Na, CL-NaH, CL-N and CL$\mathrm{NH}$ ). Reversing the precipitation process (droping the mixed rare earth chloride into precipitant solution) and keeping other preparing conditions unchanged, the products were denoted as CL-Na-R, CL-NaH-R, CL-N-R and CL-NH-R. A compared CL using urea as precipitant was also prepared. $30 \mathrm{~g} \mathrm{RECl} \cdot 6 \mathrm{H}_{2} \mathrm{O}$ was placed into 200 $\mathrm{mL}$ water together with $0.5 \mathrm{~mol}$ urea, and then stirred for $24 \mathrm{~h}$ at $90{ }^{\circ} \mathrm{C}$. The precipitate was dried and thermally treated under the same condition as above, the product was denoted as CL-Urea.

\subsection{Characterization}

The chemical composition of the catalyst was determined by inductively coupled plasma atomic emission spectroscopy (ICP- AES) using an OPTIMA 2000DV spectrometer.

The BET (Brunauer, Emmett, and Teller) surface areas of catalysts were determined on KUBO-X 1000 high performance micro analyzer by physical adsorption measurements with $\mathrm{N}_{2}$ at $-196{ }^{\circ} \mathrm{C}$. Prior to $\mathrm{N}_{2}$ physical sorption, the samples were degassed at $300{ }^{\circ} \mathrm{C}$ for $3 \mathrm{~h}$.

X-ray powder diffraction (XRD) patterns were measured using a PANalytical X'Pert Pro diffractometer with $\mathrm{Cu} \mathrm{K \alpha}(\lambda=0.15406 \mathrm{~nm})$ radiation. Data of $2 \theta$ were collected from 5 to $90^{\circ}$ with step size of $0.01^{\circ}$.

The surface morphologies of catalysts were studied using a JSM-7001F scanning electron microscope (SEM). Prior observation, the samples were covered with thin carbon film to avoid any charge accumulation on the sample surface and to improve the image contrast.

High Resolution Transmission electron microscopy (HRTEM) images were taken on a FEI Tecnai-G2-F20 microscope with EDS spectrometer. Specimens were prepared by ultrasonically suspending the sample in ethanol. Droplets of the suspension were deposited on a thin carbon film supported on a standard copper grid and dried in air.

\section{Results and discussion}

\subsection{Physicochemical properties}

ICP-AES analysis reveals that for all the catalysts, the bulk ratio of $\mathrm{La} /(\mathrm{La}+\mathrm{Ce})$ is in the range of $35.2 \sim 37.1$ mol.\%, and is very close with that in precursor (Table 1). $\mathrm{The} \mathrm{La} /(\mathrm{La}+\mathrm{Ce})$ of samples prepared from reverse coprecipitation method are a little higher than that in the samples prepared by the traditional co-precipitation using the same precipitant. The CL-Na and CL-NaH samples contained less $\mathrm{Na}^{+}$inferred that the traditional method favored precipitates washing with the same quality of deionized water, when the precipitant was excessive.
Table 1 The chemical compositions, surface area and pore volume of CL samples.

\begin{tabular}{|c|c|c|c|c|}
\hline Catalyst & $\begin{array}{c}\mathrm{La} /(\mathrm{La}+\mathrm{Ce}) \\
{[\mathrm{mol} . \%]}\end{array}$ & $\begin{array}{c}\mathrm{Na} /(\mathrm{Na}+\mathrm{La}+\mathrm{Ce}) \\
{[\text { wt. \%] }}\end{array}$ & $\begin{array}{c}\text { Surface } \\
\text { area } \\
{\left[\mathrm{m}^{2} \mathrm{~g}^{-1}\right]}\end{array}$ & $\begin{array}{c}\text { Pore } \\
\text { Volume } \\
{\left[\mathrm{cm}^{3} \mathrm{~g}^{-1}\right]}\end{array}$ \\
\hline CL-Na & 36.2 & 6.2 & 9.2 & 0.10 \\
\hline CL-Na-R & 37.1 & 15.8 & 15.4 & 0.11 \\
\hline $\mathrm{CL}-\mathrm{NaH}$ & 36.4 & 2.1 & 8.2 & 0.10 \\
\hline CL-NaH-R & 36.6 & 6.3 & 6.5 & 0.09 \\
\hline CL-N & 36.0 & - & 32 & 0.22 \\
\hline CL-N-R & 36.4 & - & 35 & 0.10 \\
\hline CL-NH & 35.2 & - & 32 & 0.08 \\
\hline CL-NH-R & 36.6 & - & 35 & 0.28 \\
\hline CL-Urea & 35.8 & - & 76 & 0.07 \\
\hline $\mathrm{RECl}_{3} \cdot 6 \mathrm{H}_{2} \mathrm{O}$ & 36.6 & - & - & - \\
\hline
\end{tabular}

The surface area and pore volume of CL samples are also summarized in Table 1. The CL-urea sample displays the largest surface area but the lowest pore volume. It can be explained by the pore size distribution results in Figure 1 that the average pare size of CL-Urea is obviously smaller than other CL samples. The pore size distribution curves of CL-N, CL-N-R, CL-NH and CLNH-R samples also have peaks at 3-5 nm, which result in higher surface area comparing to CL-Na, CL-Na-R, CL$\mathrm{NaH}$ and CL-NaH-R samples. It means that using $\left(\mathrm{NH}_{4}\right)_{2} \mathrm{CO}_{3}$ and $\mathrm{NH}_{4} \mathrm{HCO}_{3}$ as precipitant tends to produce a CL with higher surface area than using $\mathrm{Na}_{2} \mathrm{CO}_{3}$ and $\mathrm{NaHCO}_{3}$.

\subsection{Crystal structure of Catalysts}

Figure 2 presents the XRD patterns of the CL samples. Except CL-Urea, for all of the CL samples, a single diffraction peak placed at $2 \theta=10^{\circ}$ indicates the presence of $\mathrm{RE}_{8}(\mathrm{OH})_{20} \mathrm{Cl}_{4} \cdot \mathrm{nH}_{2} \mathrm{O}(\mathrm{Re}=\mathrm{Ce}, \mathrm{La})[33,34]$. For CL-Na, CL-Na-R and CL-NaH-R samples, the diffraction peak placed at $2 \theta=32^{\circ}$ is attribute to the residual $\mathrm{NaCl}$, which was not be washed clean [35]. For All of these CL samples exhibited the characteristic diffractogram of the fluorite cubic structure of $\mathrm{CeO}_{2}$ (JCPDS 34-0394) [25]. Doping of ceria with $\mathrm{La}^{3+}$ led to shifting of diffraction peaks toward lower angles as well as lower diffraction intensity [36]. This shift can be explained by the partial substitution of $\mathrm{Ce}^{4+}$ with $\mathrm{La}^{3+}$, and confirmed the formation of CL solid solution. The CL-Urea exhibited the characteristic diffractogram of $\mathrm{CL}$ solid solution without other phase, which further comfirmed urea is a suitble precipitant for co-precipitation of mixed rare earth chloride. 


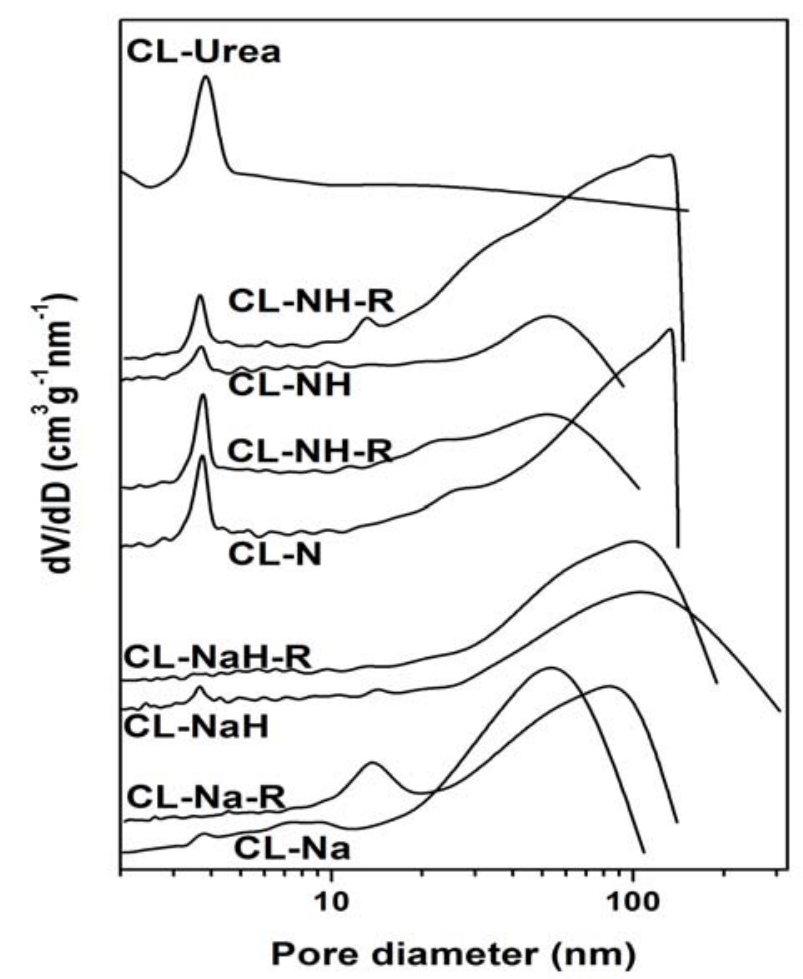

Figure 1. Pore size distribution calculated by BJH of CL samples.

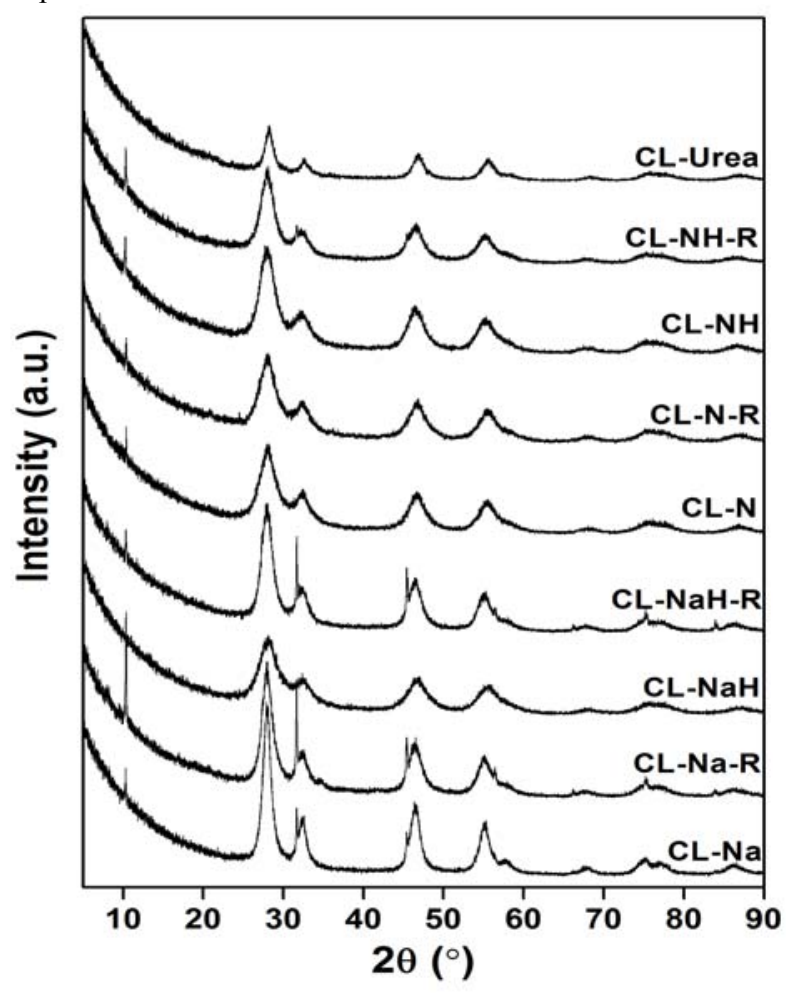

Figure 2. XRD patterns of the CL samples.

\subsection{Morphology of Catalysts}

Figure 3 shows SEM images of the CL samples. For CL$\mathrm{Na}$ and CL-Na-R samples, the impact of revese method on surface morphology of CL is more obvious than using other precipitant. The surface morphology CL-Urea sample is block-like; while for other samples, morphologies tend to flake-like.
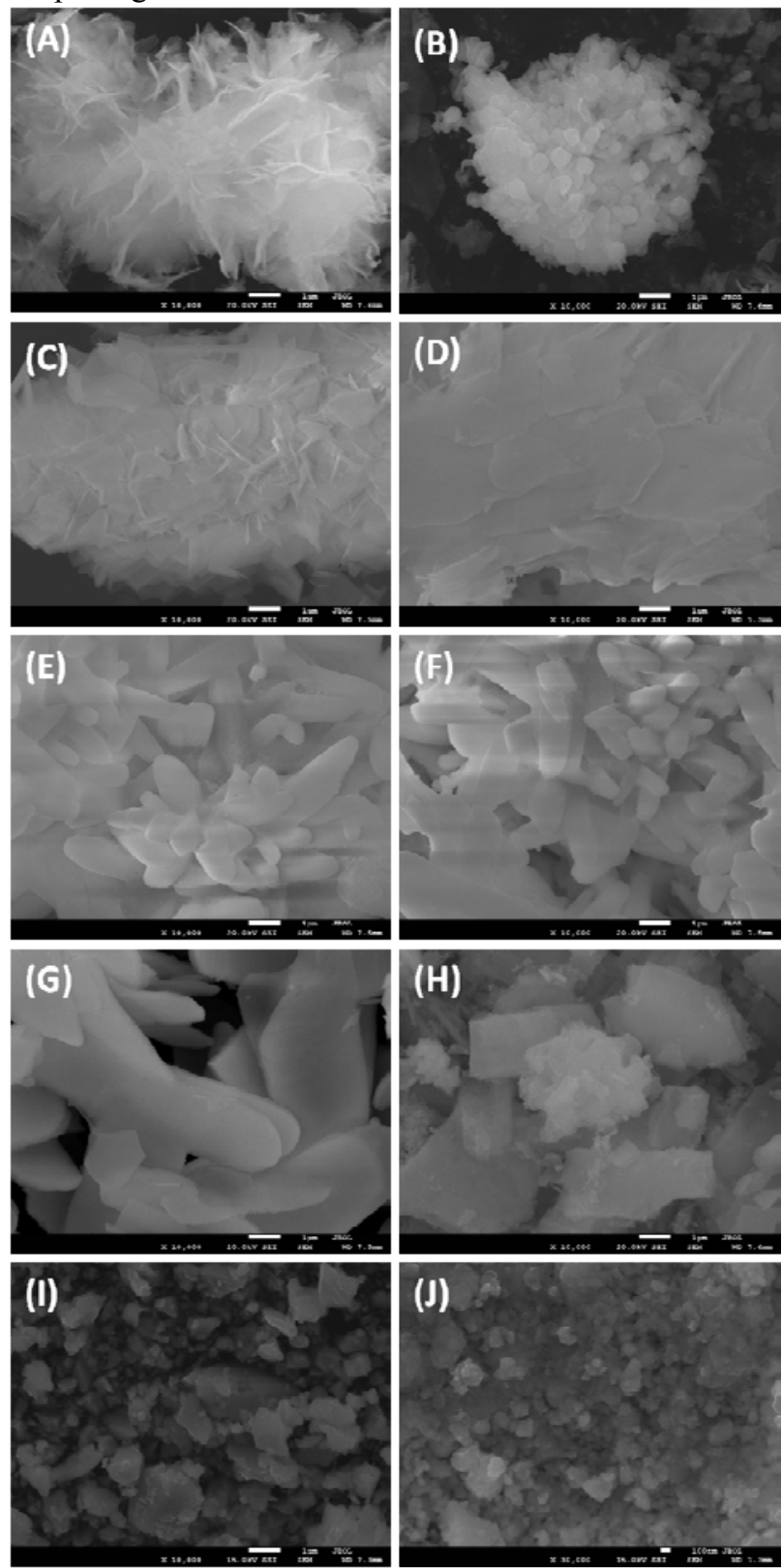

Figure 3. SEM images of CL-Na (A), CL-Na-R (B), CL-NaH (C) CL-NaH-R (D), CL-N (E), CL-N-R (F), CL-NH (G), CLNH-R (H) and CL-Urea (I, J).

The HRTEM images of CL-NH, CL-NH-R and CLUrea were showed in Figure 4. The pore in the CL-NH sample is very clear, because its thickness is very thin. The CL-Urea sample shows typical $\mathrm{Ce}_{1-\mathrm{x}} \mathrm{La}_{\mathrm{x}} \mathrm{O}_{2-\delta}(111)$ which was caculated by measuring interplanar spacing $(\mathrm{d}$ $=0.315 \AA)$. The $\mathrm{La} /(\mathrm{La}+\mathrm{Ce})$ calculated from EDS result is $37.3 \%$ (Figure $4 \mathrm{E}$ ), which is very close with that getting from ICP result. 

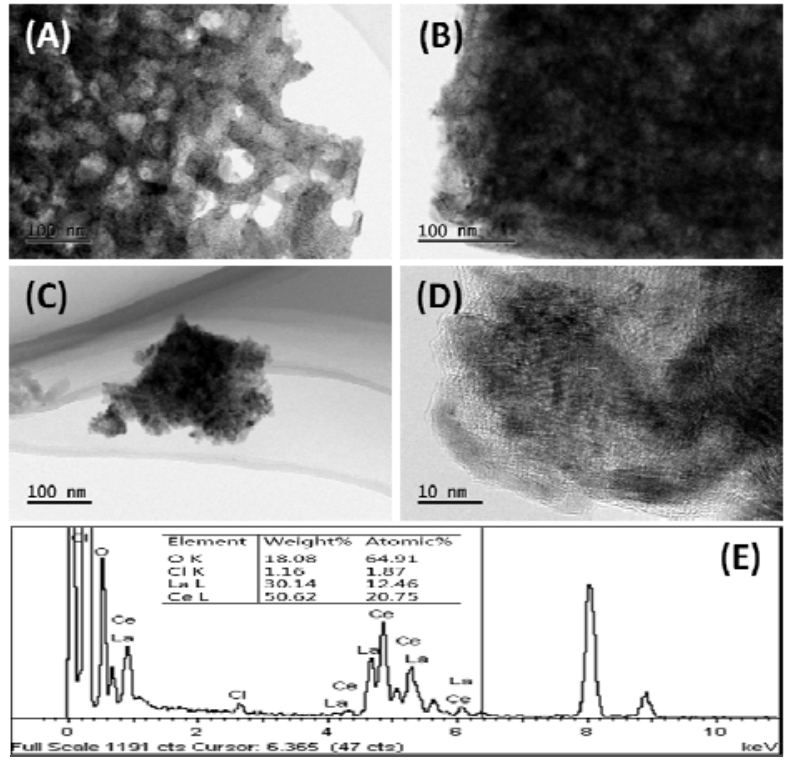

Figure 4. HRTEM images of CL-NH (A), CL-NH-R (B) and CL-Urea (C, D) samples. EDS spectra of CL-Urea sample (E).

\section{Conclusions}

The CL samples prepared by co-precipitation method using urea, $\mathrm{Na}_{2} \mathrm{CO}_{3}, \mathrm{NaHCO}_{3},\left(\mathrm{NH}_{4}\right)_{2} \mathrm{CO}_{3}$ and $\mathrm{NH}_{4} \mathrm{HCO}_{3}$ as precipitants, mixed rare earth chloride as precursor were invested. Urea was confirmed to be a suitable homogeneous precipitant, and prepared $\mathrm{CL}$ with higher surface area. $\left(\mathrm{NH}_{4}\right)_{2} \mathrm{CO}_{3}$ and $\mathrm{NH}_{4} \mathrm{HCO}_{3}$ are better traditional precipitant than the former two, which also favoured producing $\mathrm{CL}$ with higher surface area.

\section{Acknowledgements}

This work was financially supported by the National Natural Science Foundation of China (21403015) and the Program of the General Research Institute for NonFerrous Metals $(53515,53518)$.

\section{References}

[1] Y. Wei, J. Liu, Z. Zhao, A. Duan, G. Jiang, C. Xu, J. Gao, H. He, X. Wang, Energ Environ Sci 4 (2011) 2959-2970.

[2] G. Zhang, Z. Zhao, J. Xu, J. Zheng, J. Liu, G. Jiang, A. Duan, H. He, Appl Catal B 107 (2011) 302-315.

[3] C.Y. Ma, D.H. Wang, W.J. Xue, B.J. Dou, H.L. Wang, Z.P. Hao, Environ Sci Technol 45 (2011) 3628-3634.

[4] Q.J. Xu, Y.P. Zhang, J.H. Mo, X.X. Li, Environ Sci Technol 45 (2011) 5754-5760.

[5] L. Xue, H. He, C. Liu, C. Zhang, B. Zhang, Environ Sci Technol 43 (2009) 890-895.

[6] K. Harada, T. Oishi, S. Hamamoto, T. Ishihara, J Phys Chem C 118 (2014) 559-568.

[7] M. Machida, Y. Murata, K. Kishikawa, D. Zhang, K. Ikeue, Chem Mater 20 (2008) 4489-4494.

[8] B.M. Reddy, L. Katta, G. Thrimurthulu, Chem Mater 22 (2010) 467-475.
[9] Y. Wei, J. Liu, Z. Zhao, A. Duan, G. Jiang, J Catal 287 (2012) 13-29.

[10]Y. Wei, J. Liu, Z. Zhao, C. Xu, A. Duan, G. Jiang, Appl Catal A-gen 453 (2013) 250-261.

[11]J. Gimenez-Manogil, A. Bueno-Lopez, A. GarciaGarcia, Appl Catal B 152 (2014) 99-107.

[12]X. Wu, D. Liu, K. Li, J. Li, D. Weng, Catal Commun 8 (2007) 1274-1278.

[13] S. Cai, D. Zhang, L. Zhang, L. Huang, H. Li, R. Gao, L. Shi, J. Zhang, Catalysis Science \& Technology 4 (2014) 93-101.

[14]Q. Wang, B. Zhao, G. Li, R. Zhou, Environ Sci Technol 44 (2010) 3870-3875.

[15] G. Zhang, Z. Zhao, J. Liu, G. Jiang, A. Duan, J. Zheng, S. Chen, R. Zhou, Chem Commun 46 (2010) 457-459.

[16] L. Katta, P. Sudarsanam, G. Thrimurthulu, B.M. Reddy, Appl Catal B 101 (2010) 101-108.

[17]X. Han, Y. Yu, H. He, J. Zhao, Y. Wang, J Power Sources 238 (2013) 57-64.

[18]L. Katta, B.M. Reddy, M. Muhler, W. Gruenert, Catalysis Science \& Technology 2 (2012) 745-753.

[19] J.A. Rodriguez, S. Ma, P. Liu, J. Hrbek, J. Evans, M. Pérez, Science 318 (2007) 1757-1760.

[20]F.C. Meunier, D. Reid, A. Goguet, S. Shekhtman, C. Hardacre, R. Burch, W. Deng, M. FlytzaniStephanopoulos, J Catal 247 (2007) 277-287.

[21]A. Bueno-Lopez, K. Krishna, M. Makkee, J.A. Moulijn, J Catal 230 (2005) 237-248.

[22]L. Katta, T.V. Kumar, D.N. Durgasri, B.M. Reddy, Catal Today 198 (2012) 133-139.

[23] M.F. Wilkes, P. Hayden, A.K. Bhattacharya, J Catal 219 (2003) 295-304.

[24]I. Yeriskin, M. Nolan, J Chem Phys 131 (2009).

[25]B. Zhang, D. Li, X. Wang, Catal Today 158 (2010) 348-353.

[26] M.F. Wilkes, P. Hayden, A.K. Bhattacharya, J Catal 219 (2003) 286-294.

[27]W.H. Cassinelli, L.S.F. Feio, J.C.S. Araujo, C.E. Hori, F.B. Noronha, C.M.P. Marques, J.M.C. Bueno, Catal Lett 120 (2008) 86-94.

[28]Q. Fu, W.L. Deng, H. Saltsburg, M. FlytzaniStephanopoulos, Appl Catal B 56 (2005) 57-68.

[29] Q. Fu, H. Saltsburg, M. Flytzani-Stephanopoulos, Science 301 (2003) 935-938.

[30] K.C. Petallidou, A.M. Efstathiou, Appl Catal B 140 (2013) 333-347.

[31]X. Han, Y. Yu, H. He, W. Shan, Int J Hydrogen Energy 38 (2013) 10293-10304.

[32] V. Bellière, G. Joorst, O. Stephan, F.M.F. de Groot, B.M. Weckhuysen, The Journal of Physical Chemistry B 110 (2006) 9984-9990.

[33] M. Jobbagy, C. Sorbello, E.E. Sileo, J Phys Chem C 113 (2009) 10853-10857.

[34]F. Geng, Y. Matsushita, R. Ma, H. Xin, M. Tanaka, F. Izumi, N. Iyi, T. Sasaki, J Am Chem Soc 130 (2008) 16344-16350.

[35]T. Tsuzuki, P.G. McCormick, J Am Chem Soc 84 (2001) 1453-1458.

[36] M.F. Wilkes, P. Hayden, A.K. Bhattacharya, J Catal 219 (2003) 305-309. 